\title{
Total Antioxidant Capacity in HBV Carriers, a Promising Biomarker for Evaluating Hepatic Fibrosis: A Pilot Study
}

\author{
Jing-Hua Wang ${ }^{1}{ }^{\oplus}$, Sung-Bae Lee ${ }^{1}$, Dong-Soo Lee ${ }^{2}$ and Chang-Gue Son ${ }^{1, *}$ \\ 1 Institute of Bioscience \& Integrative Medicine, Daejeon University, 75, Daedeok-daero 176, Seo-gu, \\ Daejeon 35235, Korea; ewccwang@gmail.com (J.-H.W.); sky161300@naver.com (S.-B.L.) \\ 2 Department of Internal Medicine, Daejeon St. Mary's Hospital, College of Medicine, \\ The Catholic University of Korea, 64, Daeheung-ro, Jung-gu, Daejeon 34943, Korea; endoscope@hanmail.net \\ * Correspondence: ckson@dju.ac.kr; Tel.: +82-42-229-6723; Fax: +82-42-257-6398
}

check for

updates

Citation: Wang, J.-H.; Lee, S.-B.; Lee, D.-S.; Son, C.-G. Total Antioxidant Capacity in HBV Carriers, a

Promising Biomarker for Evaluating Hepatic Fibrosis: A Pilot Study.

Antioxidants 2021, 10, 77.

https://doi.org/10.3390/

antiox10010077

Received: 9 December 2020

Accepted: 7 January 2021

Published: 8 January 2021

Publisher's Note: MDPI stays neutral with regard to jurisdictional clai$\mathrm{ms}$ in published maps and institutional affiliations.

Copyright: (C) 2021 by the authors. Licensee MDPI, Basel, Switzerland. This article is an open access article distributed under the terms and conditions of the Creative Commons Attribution (CC BY) license (https:// creativecommons.org/licenses/by/ $4.0 /)$.

\begin{abstract}
Oxidative stress plays a pivotal role in the progression of chronic hepatitis B; however, it is unclear whether the status of blood oxidative stress and antioxidant components differs depending on the degree of hepatic fibrosis. To explore the relationship between oxidative stress/antioxidant capacity and the extent of hepatic fibrosis, fifty-four subjects with liver fibrosis $(5.5 \leq$ liver stiffness measurement $(\mathrm{LSM})$ score $\leq 16.0 \mathrm{kPa}$ ) by chronic hepatitis B virus (HBV) were analyzed. From the analysis of eight kinds of serum oxidative stress/antioxidant profiles and liver fibrosis degrees, the level of total antioxidant capacity (TAC) reflected a negative correlation with the severity of hepatic fibrosis (Pearson correlation, $\mathrm{r}=-0.35, p=0.01)$. Moreover, TAC showed higher sensitivity $(73.91 \%)$ than the aspartate transaminase (AST) to platelet ratio index (APRI, 56.52\%) in the receiver operating characteristic (ROC) curves. Interestingly, the TAC level finely reflected the fibrosis degree in inactive carriers (HBV DNA < $2000 \mathrm{IU} / \mathrm{mL}$ ), while the APRI did in active carriers (HBV DNA > $2000 \mathrm{IU} / \mathrm{mL}$ ). In conclusion, TAC is a promising biomarker for evaluating the progression of liver fibrosis in patients with $\mathrm{HBV}$, and this finding may indicate the involvement of TAC-composing factors in the pathogenesis of hepatic fibrosis in chronic HBV carriers.
\end{abstract}

Keywords: hepatitis B virus; oxidative stress; total antioxidant capacity; liver fibrosis; liver stiffness measurement; AST to platelet index

\section{Introduction}

Generally, chronic liver disease can be induced by a variety of causes, including hepatitis B virus (HBV) infection [1]. Meanwhile, it has been conservatively estimated that two billion people have been infected with HBV, and that at least 400 million have become HBV carriers worldwide [2]. In highly endemic areas, HBV has been a predominant cause of chronic liver diseases, including hepatic fibrosis, cirrhosis, and cancer. Although global vaccination has rapidly lowered the $H B V$ infection rate worldwide [3], chronic hepatitis $B$ is still a considerable public health issue, as the seventh highest cause of death worldwide, especially in South Korea and China [3,4]. In addition, the progression of hepatic fibrosis is a critical pathologic step determining the clinical outcome in subjects with chronic liver disease, including HBV infection [5,6]. Chronic HBV infection is a typical cause of liver fibrogenesis. Previous clinical studies reported that $20 \%$ to $30 \%$ of HBV carriers with normal alanine transaminase (ALT) levels and high HBV DNA load had hepatic fibrosis [7].

Regarding the hepatic fibrosis-related pathologic process, oxidative stress is mostly adapted as a common contributor [8,9]. Oxidative stress is a ubiquitous phenomenon that exists in most living organisms and is characterized by a loss of equilibrium between free radicals such as reactive oxygen species (ROS) and antioxidant capacity [10,11]. Although moderate oxidative stress exerts an essential role in physiological processes, such as intracellular signal transduction and a natural defense against pathogenic microorganisms [12,13], supraphysiological oxidative stress is undoubtedly implicated in the initiation 
or progression of numerous disorders, including liver fibrosis [11]. Therefore, antioxidative therapy is frequently used for chronic hepatic disorders and has been used to protect against liver fibrosis in many clinical trials [14,15].

In the clinical field of hepatic fibrosis, in addition to the development of antifibrotic agents, the rapid and accurate assessment of the stage of liver fibrosis is a very important issue [16]. To date, liver biopsy remains to be the gold standard for the diagnosis of liver fibrosis; however, invasive operation, sampling error, and cost seriously limit its widespread and frequent use in clinics. Fortunately, a novel noninvasive tool, namely, liver stiffness measurement (LSM) by transient elastography technology (e.g., FibroScan, Echosens, Paris, France), has been developed to estimate liver scarring with high accuracy [17]. In addition, noninvasive biomarkers have been commonly utilized, such as the aspartate transaminase (AST) to platelet ratio index (APRI), fibrosis-4 (FIB-4), and hyaluronic acid (HA), which are created based on the pathophysiological features of hepatic fibrosis [18,19]. Among those, the APRI, which reflects the decrease in blood platelet number and increase in serum levels of AST in hepato-fibrotic changes, has been mostly preferred for detecting liver fibrosis/cirrhosis [20].

Numerous studies have indicated that oxidative stress is excessive in patients with chronic HBV hepatitis as compared with healthy subjects [21], but the comprehensive profiling of oxidative stress and antioxidative status within HBV carriers according to liver fibrosis degree is still unclear. It is worth noting whether oxidative stress/antioxidantrelated parameters can be used as reliable predictive factors for assessing liver fibrosis in HBV carriers. Therefore, we analyzed the serum oxidative/antioxidative profiles comparing hepatofibrotic severity among chronic HBV carriers and verified the correlations in mild to moderate/severe levels of liver fibrosis.

\section{Subjects and Methods}

\subsection{Subjects and Study Design}

Ethical approval for the study was obtained from the institutional ethics committee of the Daejeon University Dunsan Hospital (DJMC200901) and the Daejeon St. Mary's Hospital of Catholic University of Korea (DC12MDMT0041), and all methods were performed according to the relevant guidelines and regulations of the institution. Voluntary written informed consent was obtained from all participants. HBV virus-infected participants (aged 18-65 years) with disorders with a $5.5 \leq$ LSM score $\leq 16.0 \mathrm{kPa}$ using FibroScan were recruited (Table 1). However, participants with marked liver cirrhosis ( $>16.0 \mathrm{kPa}$ of LSM) who took immunosuppressive, antioxidative, and anti-inflammatory drugs; cytotoxic drugs; or hormone therapy were excluded from this study. Detailed inclusion/exclusion criteria are shown in the Supplementary Materials (Table S1). Blood samples were collected from all subjects after an overnight fast of at least $8 \mathrm{~h}$. The serum was separated under reactive centrifugal force $(\mathrm{RCM})$ centrifugation at $3000 \times \mathrm{g}$ for $15 \mathrm{~min}$ at $4{ }^{\circ} \mathrm{C}$ and eventually stored at $-80{ }^{\circ} \mathrm{C}$ for future determination.

\subsection{Liver Stiffness Measurement by FibroScan}

FibroScan (Echosence, Paris, France), a noninvasive liver fibrosis diagnostic tool using transient elastography technology, was used in this study to evaluate the extent of liver fibrosis. All FibroScan tests were performed after overnight fasting. To compare the oxidative/antioxidant parameters in accordance with the level of hepatofibrosis, we divided subjects into two groups by LSM score, i.e., from $8.5 \mathrm{kPa}$ to $16.0 \mathrm{kPa}$ versus from $5.5 \mathrm{kPa}$ to $8.5 \mathrm{kPa}$, on the basis of a previous study [22].

\subsection{Complete Blood Count, Fasting Blood Glucose, and Serum Biochemical Analysis}

The complete blood count (CBC) was determined using an automated hematology analyzer (Sysmex XE-2100, Kobe, Japan). The fasting blood glucose (FBG) levels were checked by Accu-Chek Glucometer (Roche Diabetes Care GmbH, Mannheim, Germany). The serum levels of alkaline aspartate transaminase (AST), alanine transaminase (ALT), ala- 
nine phosphatase (ALP), total protein, albumin, uric acid (UA), bilirubin, total cholesterol, high-density lipoprotein (HDL), and triglyceride (TG) were measured by an autochemistry analyzer (Chiron, Emeryville, CA, USA). The levels of serum hyaluronic acid (HA), transforming growth factor beta (TGF- $\beta$ ), and platelet-derived growth factor (PDGF) were analyzed by commercial ELISA kits (R\&D Systems, Minneapolis, MN, USA).

Table 1. Characteristics of participants with hepatitis B virus (HBV).

\begin{tabular}{|c|c|c|c|}
\hline Characteristics & Male & Female & Total \\
\hline Subject number & 44 & 10 & 54 \\
\hline Median age (year, range) & $51(36-66)$ & $54(45-65)$ & $52(36-66)$ \\
\hline Average height (cm, range) & $170(158-180)$ & 159 (155-174) & $168(155-180)$ \\
\hline Average weight (kg, range) & $69.5(49.6-87.0)$ & $57.5(43.0-70.9)$ & $67(43.0-87.0)$ \\
\hline Mean BMI (value, range) & $24.0(18.4-29.4)$ & $22.8(18.1-27.2)$ & $23.8(18.1-29.4)$ \\
\hline Antiviral drug $+/-$ & $27 / 17$ & $8 / 2$ & $35 / 19$ \\
\hline HBV DNA viral load (IU/mL, n) & $<2000,29 ;>2000,15$ & $<2000,6 ;>2000,4$ & $<2000,34 ;>2000,20$ \\
\hline \multicolumn{4}{|l|}{ Blood/Serum parameters } \\
\hline Average AST (U/L) & $31(15-83)$ & $30(19-60)$ & $31(15-83)$ \\
\hline Average ALT (U/L) & $34(16-166)$ & $29(14-68)$ & $33(14-166)$ \\
\hline Average GGT (U/L) & $37(11-208)$ & $18(8-37)$ & $34(8-208)$ \\
\hline Mean Platelets $\left(10^{10} / \mathrm{L}\right)$ & $18.1(8.0-36.4)$ & $13.0(8.3-19.1)$ & $17.2(8.0-36.4)$ \\
\hline Average FBG (mg/dL) & $103(81-149)$ & $100(72-122)$ & $103(72-149)$ \\
\hline \multicolumn{4}{|l|}{ Liver fibrotic biomarkers } \\
\hline Average LSM (kPa, range) & $8.6(5.5-15.5)$ & $7.7(5.6-10.1)$ & $8.4(5.5-15.5)$ \\
\hline Mean APRI (value, range) & $0.46(0.15-1.0)$ & $0.64(0.28-1.44)$ & $0.49(0.15-1.44)$ \\
\hline Mean FIB-4 (score, range) & $1.71(0.74-5.2)$ & $2.65(1.16-4.69)$ & $1.89(0.74-5.2)$ \\
\hline Mean HA (ng/mL, range) & $44(2-338)$ & $51(4-145)$ & $45(2-338)$ \\
\hline
\end{tabular}

BMI, body mass index; AST, alkaline aspartate transaminase; ALT, alanine transaminase; GGT, gamma glutamyl transpeptidase; FBG, fasting blood glucose; LSM, liver stiffness measurement; APRI, AST to platelet ratio index; FIB-4, fibrosis-4; HA, hyaluronic acid.

\subsection{Serum Lipid Peroxide Determination}

The serum lipid peroxide levels were measured using thiobarbituric acid reactive substances (TBARS), according to the modified Satoh's method [23]. Briefly, the TBARS concentration was expressed as $\mu \mathrm{M}$ malondialdehyde (MDA) in serum. One hundred microliters of undiluted serum or various concentrations of 1,1,3,3-tetraethoxypropane (TEP) as a standard was added to $500 \mu \mathrm{L}$ of $0.02 \%$ trichloroacetic acid (TCA) for a $10 \mathrm{~min}$ incubation, mixed with $500 \mu \mathrm{L}$ of sulfuric acid and $600 \mu \mathrm{L}$ of $20 \mathrm{mg} / \mathrm{dL}$ thiobarbituric acid (TBA) in $2 \mathrm{M}$ sodium sulfate, heated at $100^{\circ} \mathrm{C}$ for $60 \mathrm{~min}$, cooled on ice for $10 \mathrm{~min}$, centrifuged to remove the supernatant, and vigorously vortexed with $300 \mu \mathrm{L}$ of n-butanol. After centrifugation at $3000 \times g$ for $10 \mathrm{~min}$, the absorbance of the upper organic layer was detected at $530 \mathrm{~nm}$ with a spectrophotometer (Molecular Devices, Sunnyvale, CA, USA) and was compared with the TEP standard curve.

\subsection{Serum Total Reactive Oxygen Species Determination}

Total reactive oxygen species (ROS) is a primary cause of oxidative stress [24]. In order to assess the whole status of oxidative stress in vivo, the serum ROS level was assayed by using Hayashi's method [25]. In brief, $5 \mu \mathrm{L}$ of undiluted serum or different concentration of hydrogen peroxide $\left(\mathrm{H}_{2} \mathrm{O}_{2}\right)$ standard solution was mixed with $140 \mu \mathrm{L}$ of $0.1 \mathrm{M}$ sodium acetate buffer ( $\mathrm{pH} 4.8)$ in a 96-well plate at room temperature, and then the mixture was incubated at $37^{\circ} \mathrm{C}$ for $5 \mathrm{~min}$. The $100 \mu \mathrm{L}$ of $10 \mathrm{mM} \mathrm{N}, \mathrm{N}$-diethyl-para-phenylenediamine (DEPPD) and $4.37 \mu \mathrm{M}$ ferrous sulfate mixture $(1: 25, v / v)$ was added to each well, and after preincubation at $37^{\circ} \mathrm{C}$ for $1 \mathrm{~min}$, the level of serum ROS was determined at $505 \mathrm{~nm}$ using a spectrophotometer (Molecular Devices). 


\subsection{Serum Superoxide Dismutase Determination}

The serum superoxide dismutase (SOD) activity was determined spectrophotometrically using a commercial SOD assay kit (Dojindo Laboratories, Kumamoto, Japan). One unit of SOD activity was defined as the quantity of enzyme inhibiting the reduction reaction of highly water-soluble tetrazolium salt, namely WST-1 (2-(4-Iodophenyl)-3-(4-nitrophenyl)-5(2,4-disulfophenyl)-2H-tetrazolium, monosodium salt), with superoxide anion. According to the manufacturer's technical manual, absorbance was measured at $450 \mathrm{~nm}$ using a spectrophotometer (Molecular Devices). A series dilution of lyophilized bovine erythrocyte SOD was used to make a standard curve ranging from 0 to $50 \mathrm{U} / \mathrm{mL}$.

\subsection{Serum Catalase Determination}

The serum catalase peroxidatic activity was evaluated by Wheeler's method [26]. Briefly, phosphatase buffer ( $30 \mu \mathrm{L}, 250 \mathrm{mM}, \mathrm{pH} 7.0)$, methanol $(30 \mu \mathrm{L}, 12 \mathrm{mM})$ and $\mathrm{H}_{2} \mathrm{O}_{2}$ $(30 \mu \mathrm{L}, 44 \mathrm{mM}$ ) were mixed together with diluted serum samples or catalase standard solutions in 96-well plates. After $10 \mathrm{~min}$ of incubation at RT, the reaction was stopped by adding Purpald solution $(90 \mu \mathrm{L}, 22.8 \mathrm{mM}$ Purpald in $2 \mathrm{~N}$ potassium hydroxide). After adding the potassium peroxide solution ( $30 \mu \mathrm{L}, 65.2 \mathrm{mM}$ in $0.5 \mathrm{~N}$ potassium hydrate), the mixture was incubated for $10 \mathrm{~min}$ at RT. The absorbance of the purple formaldehyde adduct was measured at $550 \mathrm{~nm}$ using a spectrophotometer (Molecular Devices)

\subsection{Serum Total Glutathione Content, Glutathione Peroxidase, and Glutathione Reductase Activity Determination}

The serum glutathione (GSH) content was assessed by an EZ-Glutathione Assay Kit (DoGen Bio Co., Ltd., Seoul, Korea). Glutathione peroxidase (GPx) and glutathione reductase (GRed) were determined using the glutathione peroxidase cellular activity assay kit and glutathione reductase assay kit, respectively (Sigma-Aldrich, St. Louis, MO, USA). The above assays were performed strictly following the manufacturer's instructions.

\subsection{Serum Total Antioxidant Capacity Assay}

The serum total antioxidant capacity (TAC) was evaluated using Kambsyashi's method [27]. Briefly, $90 \mu \mathrm{L}$ of $10 \mathrm{mM}$ phosphate-buffered saline (PBS, pH 7.2), $50 \mu \mathrm{L}$ of $18 \mu \mathrm{M}$ myoglobin solution and $20 \mu \mathrm{L}$ of $3 \mathrm{mM} \mathrm{2,2'-azino-bis} \mathrm{(3-ethylbenzthiazoline-6-sulfonic} \mathrm{acid)}$ diammonium salt (ABTS) solution were mixed simultaneously with two times diluted serum samples or various concentrations of standard gallic acid solution for $3 \mathrm{~min}$ at room temperature (RT). Then, the reaction was started by adding $20 \mu \mathrm{L}$ of $30 \% \mathrm{H}_{2} \mathrm{O}_{2}$ and incubating for $5 \mathrm{~min}$ at RT. The absorbance measurements were performed by using a microplate reader (Molecular Device, CA, USA) at $600 \mathrm{~nm}$. The TAC was expressed as the gallic acid equivalent antioxidant capacity (GEAC).

\subsection{Statistical Analysis}

All results are expressed as the mean \pm standard deviation. The statistical package for science software (SPSS, 17.0 version, Chicago, IL, USA) was used for statistical analyses. The statistical significance of differences was analyzed using Student's $t$-test. The relationship strength among parameters was assessed by the two-tailed Pearson's correlation test. A value of Pearson's correlation coefficient $r>0.3$ or $<-0.3$ was considered to be a significant positive or negative correlation, respectively. To determine the diagnostic utility of related parameters, receiver operating characteristic (ROC) curves and the area under the curve (AUC) were analyzed by MedCalc Statistical software (version 19.1); $p<0.05$ was considered to indicate a significant difference.

\section{Results and Discussion}

Chronic HBV infection is deemed to be one of the major causes of liver fibrogenesis $[28,29]$. Although multiple studies have shown that liver fibrosis can be mediated by oxidative stress [30,31], it is still unclear whether serum redox biomarkers can be used to evaluate 
or predict the development of liver fibrosis and subsequent cirrhosis in HBV carriers. To answer this question, from two hospitals, we enrolled 54 subjects (44 males and 10 females) with liver fibrosis caused by chronic HBV. The median age and mean body mass index (BMI) were 52 years (males 51 and females 54) and 23.8 (males 24.0 and females 22.8), respectively. In this study, the inclusive range for liver fibrosis was set to $5.5 \leq \mathrm{LSM}$ score $\leq 16 \mathrm{kPa}$, and the average LSM was $8.4 \mathrm{kPa}$ (males 8.6 and females 7.7) (Table 1). Even if the LSM score varies with the causative diseases, this LSM range is generally considered to conform to the $2 \leq \mathrm{F} \leq 3$ METAVIR score (a commonly used tool for assessing the severity of hepatic fibrosis) (F0, no fibrosis; F1, portal fibrosis; F2, portal fibrosis with few septa; F3, septal fibrosis; F4, cirrhosis on histologic examination) [32]. In a previous study of 530 adults, the mean LSM of healthy subjects was $4.1 \mathrm{kPa}$, while it was $3.4 \mathrm{kPa}$ in the elderly (>55 years) group [33].

Serum TAC (A) and the APRI (D) were compared according to the LSM score (LSM > 8.5 or $<8.5)$. The serum TAC values (B) were negatively correlated with the LSM scores in HBV carriers, and the APRI (E) was positively correlated with the LSM scores in HBV carriers. Receiver operating characteristic (ROC) curves were employed for the prediction of moderate/severe liver fibrosis (LSM > 8.5) using (C) TAC and (F) the APRI. LSM scores were compared according to the values of TAC $(\mathrm{G})$ and the APRI $(\mathrm{H})$ based on halves or quartiles, respectively (from low to high value).

To explore the features of oxidative/antioxidant parameters by the level of hepatofibrosis, we divided subjects into two groups, i.e., $5.5 \mathrm{kPa} \leq \mathrm{LSM} \leq 8.5 \mathrm{kPa}$ versus $8.5 \mathrm{kPa}$ $<\mathrm{LSM} \leq 16.0 \mathrm{kPa}$. A previous clinical study had reported that $8.5 \mathrm{kPa} \mathrm{LSM}$ was a cutoff score for bridging fibrosis in 900 chronic viral hepatitis subjects [22]. Then, we compared oxidative stress-related parameters in serum, such as ROS, MDA, TAC, SOD, catalase, GSH, GPx, and GRd. Among these, four antioxidant parameters (TAC, catalase, GSH, and GPx) showed a tendency of reduction in the LSM $>8.5 \mathrm{kPa}$ group, while two oxidative parameters (ROS and MDA) did not reveal any change. Interestingly, TAC showed a significant difference according to the LSM classification ( $p=0.01$, Figure $1 \mathrm{~A}$ and Table 2$)$. When we performed Pearson correlation analysis, we also found a significant correlation between TAC levels and LSM scores in all 54 subjects $(r=-0.35, p=0.01$, Figure $1 \mathrm{~B})$. When we compared those oxidative parameters with known hepatofibrotic markers, including the APRI, FIB-4, and HA, the APRI (but not FIB-4 and HA) also revealed differences according to the 2-grouped LSM scores ( $p=0.03$, Figure 1D and Table 2 ) and showed a significant correlation with the LSM score $(\mathrm{r}=0.34, p=0.01$, Figure 1E). As expected, the LSM scores (hepatofibrosis) were distinguished in the reverse setting using the median values of TAC or APRI ( $p=0.04$ for TAC, $p=0.01$ for APRI, Figure $1 G, H)$. In particular, the TAC levels gradually decreased depending on the increase in LSM scores among the four groups, as further consistently compared to the APRI (Figure $1 \mathrm{G}, \mathrm{H})$.

The levels of TAC (A), APRI (B), FIB-4 (C), and HA (D) were compared within the active (viral DNA load $>2000 \mathrm{IU} / \mathrm{mL}$ ) or inactive (viral DNA load $<2000 \mathrm{IU} / \mathrm{mL}$ ) HBV carriers according to the LSM score $(\mathrm{LSM}>8.5$ or $<8.5)$.

Commonly, the ROC curve in logistic regression is a useful approach to predict whether an observation is true or false [34]. Our results of ROC analysis indicated that TAC possessed a sensitivity of $73.91 \%$ and a specificity of $64.52 \%(p<0.02$, Figure $1 C)$ for the detection of severe fibrosis in patients with chronic HBV infection; moreover, the APRI also showed a sensitivity of $56.52 \%$ and a specificity of $77.42 \%(p<0.08$, Figure $1 \mathrm{~F})$. Thus, the combination of the APRI and TAC can be used as a predictor of liver fibrosis degree in HBV carriers due to the simple, rapid, economic and relatively accurate characteristics; moreover, TAC had a higher sensitivity (true positive rate) and more significance for estimating liver fibrosis than the APRI. While the APRI possessed a relatively higher specificity (true negative rate) than TAC, the APRI and TAC might be recommended for simultaneous use in a clinic. 
A

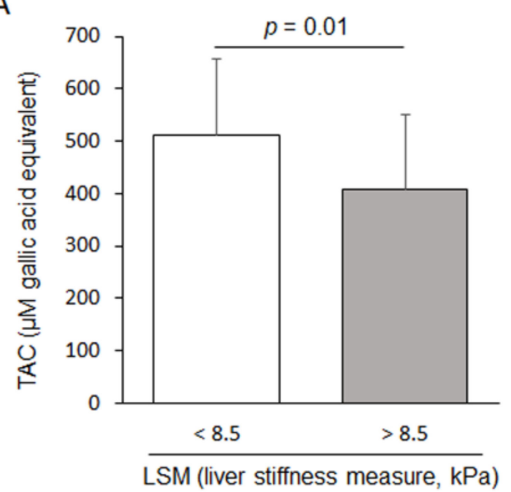

D

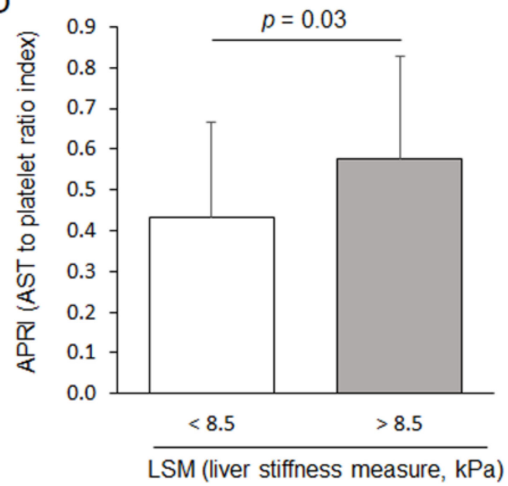

G

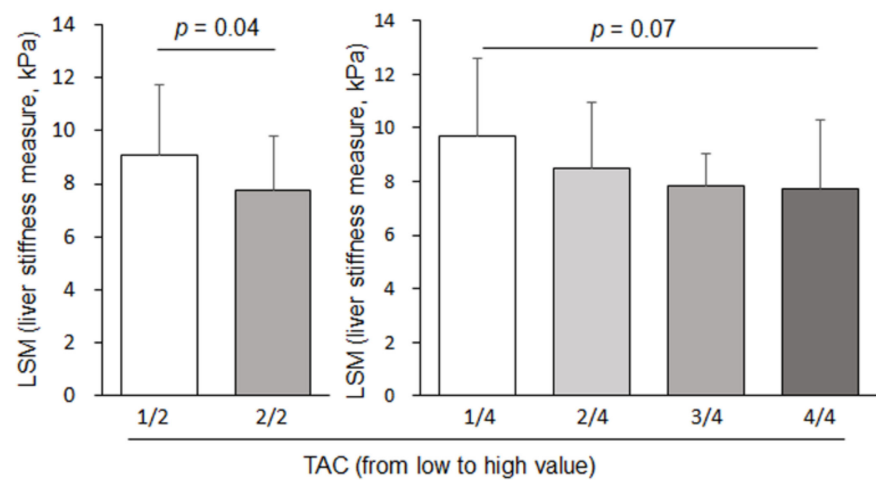

B

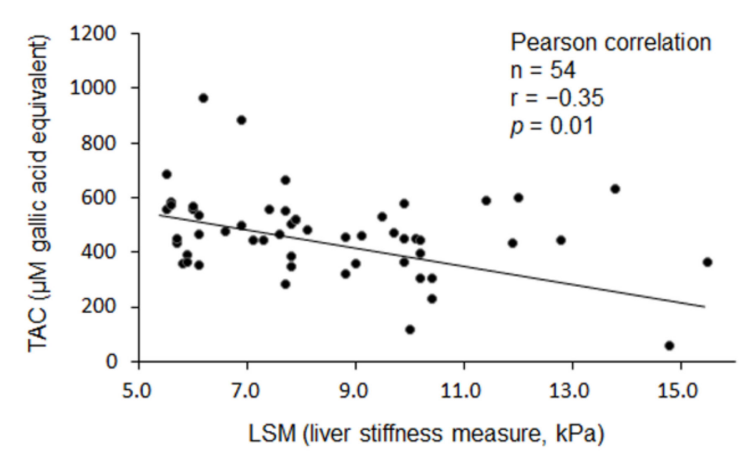

E

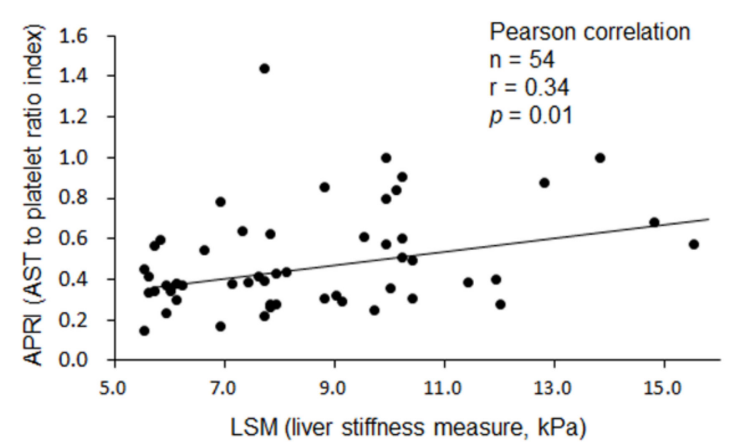

$\mathrm{H}$

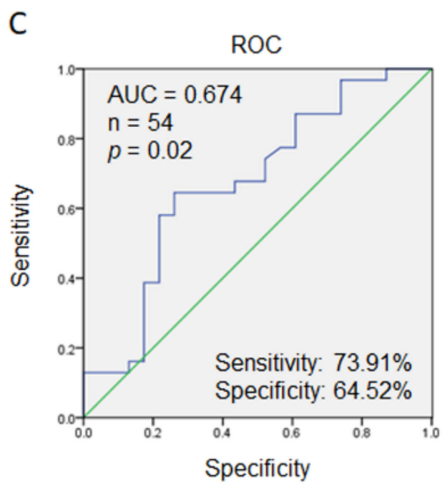

F

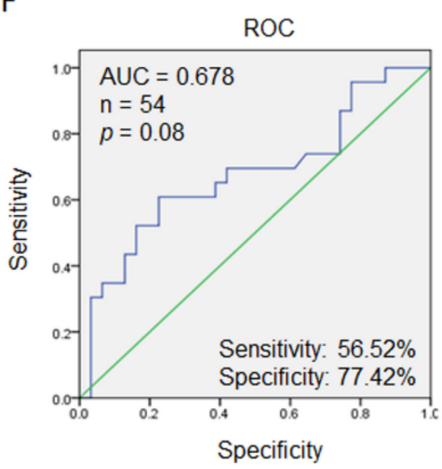

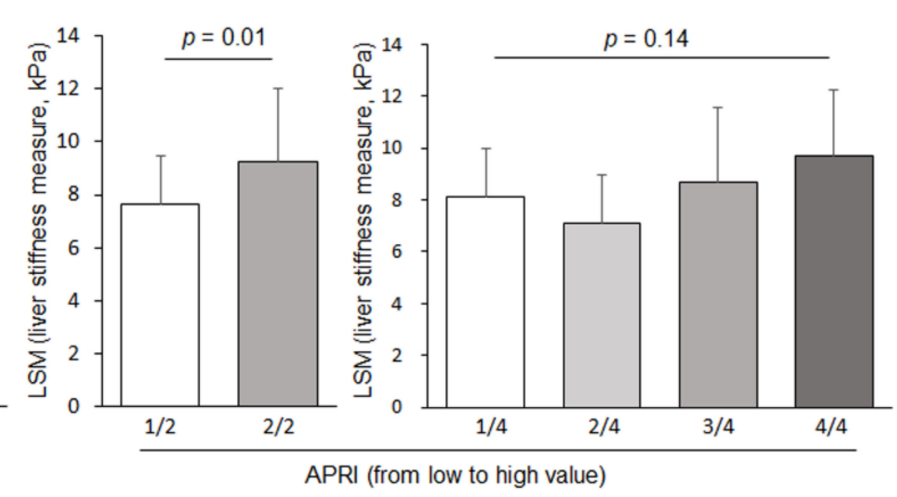

Figure 1. Serum total antioxidant capacity (TAC) and aspartate transaminase (AST) to platelet ratio index (APRI) for predicting moderate/severe liver fibrosis within HBV carriers. Serum TAC (A) and the APRI (D) were compared according to the LSM score (LSM > 8.5 or < 8.5). Serum TAC values $($ B) were negatively correlated with LSM scores in HBV carriers, and the APRI (E) was positively correlated with LSM scores in HBV carriers. Receiver operating characteristic (ROC) curves were employed for the prediction of moderate/severe liver fibrosis (LSM > 8.5) using (C) TAC and (F) the APRI. LSM scores were compared according to the values of TAC $(\mathbf{G})$ and the APRI $(\mathbf{H})$ based on halves or quartiles, respectively (from low to high value).

In general, most previous studies have reported that serum ROS, lipid peroxidation, SOD, GSH, and catalase were markedly changed in HBV carriers as compared with healthy controls [21,35]; however, few studies have compared HBV carriers [36]. No notable difference was observed in oxidative stress-related markers between the mild and moderate/severe liver fibrosis groups (Table 2), but we found a significant change in TAC levels in the present study. Actually, the measurement of TAC is merely a reductionist method for evaluating the scavenging capacity of free radicals and predicting holistic antioxidant capacity in vivo [37], which is different from the determination of endogenous antioxidant components, such as SOD, GSH, and catalase [38]. Generally, albumin and uric acid dominantly exert free radical scavenging properties in human serum more than other 
intraserous components, such as ascorbic acid and $\alpha$-tocopherol [39]. Clinical studies have reported lower serum albumin levels in liver cirrhosis and a negative correlation between hyperuricemia and liver disease severity in subjects with chronic viral hepatitis $[40,41]$. In our data, both the serum albumin and uric acid levels were within the normal range, and no difference was observed between the two groups (Table 2). These results indicated the noninvolvement of serum albumin and uric acid in the decreased TAC level in liver fibrosis progression. However, the quality-related aspect of serum albumin would affect the lower TAC results in the moderate/severe fibrosis group. One study reported that the heterogeneity of albumin showed distinct redox potential in vitro [42]. We also found no significant difference in FBG levels between the mild and moderate/severe liver fibrosis groups (Table 2).

Table 2. Parameter changes according to the liver stiffness measurement (LSM) score.

\begin{tabular}{|c|c|c|c|c|c|c|c|}
\hline \multirow{4}{*}{ Measurements } & \multirow{2}{*}{\multicolumn{3}{|c|}{$\begin{array}{c}\text { Mild Hepatic Fibrosis } \\
\text { LSM }<8.5 \mathrm{kPa}\end{array}$}} & \multirow{2}{*}{\multicolumn{3}{|c|}{$\begin{array}{c}\text { Moderate/Severe Hepatic Fibrosis } \\
\text { LSM }>8.5 \mathrm{kPa}\end{array}$}} & \multirow{2}{*}{$t$-Test } \\
\hline & & & & & & & \\
\hline & \multicolumn{3}{|c|}{ Total 31 (M/F:23/8) } & \multicolumn{3}{|c|}{ Total 23 (M/F:21/2) } & \multirow{2}{*}{$p$ Value } \\
\hline & Mean & & SD & Mean & & SD & \\
\hline $\mathrm{LSM}(\mathrm{kPa})$ & 6.7 & \pm & 0.9 & 10.8 & \pm & 1.8 & 0.00 \\
\hline $\mathrm{TAC}(\mu \mathrm{M} / \mathrm{mL})$ & 511.5 & \pm & 144.4 & 406.8 & \pm & 143.5 & 0.01 \\
\hline $\operatorname{MDA}(\mu \mathrm{M} / \mathrm{mL})$ & 77.5 & \pm & 40.2 & 79.4 & \pm & 52.7 & 0.89 \\
\hline $\mathrm{ROS}(\mathrm{U} / \mathrm{mL})$ & 23.7 & \pm & 5.1 & 23.4 & \pm & 6.6 & 0.84 \\
\hline $\mathrm{SOD}(\mathrm{U} / \mathrm{mL})$ & 6.1 & \pm & 3.4 & 6.0 & \pm & 2.7 & 0.90 \\
\hline Catalase $(\mathrm{U} / \mathrm{mL})$ & 5.9 & \pm & 2.7 & 4.9 & \pm & 2.1 & 0.13 \\
\hline $\mathrm{GSH}(\mu \mathrm{M} / \mathrm{mL})$ & 2.4 & \pm & 1.3 & 2.1 & \pm & 0.9 & 0.29 \\
\hline GPx $(\mathrm{U} / \mathrm{mL})$ & 100.8 & \pm & 50.9 & 88.8 & \pm & 33.0 & 0.30 \\
\hline GRed (U/mL) & 49.8 & \pm & 17.2 & 50.1 & \pm & 25.8 & 0.96 \\
\hline APRI & 0.4 & \pm & 0.2 & 0.6 & \pm & 0.3 & 0.03 \\
\hline FIB-4 & 1.7 & \pm & 0.9 & 2.2 & \pm & 1.1 & 0.09 \\
\hline HA (ng/mL) & 41.9 & \pm & 34.5 & 49.6 & \pm & 70.2 & 0.63 \\
\hline TGF- $\beta 1$ (ng/mL) & 1.3 & \pm & 1.1 & 1.5 & \pm & 0.9 & 0.47 \\
\hline PDGF (ng/mL) & 0.6 & \pm & 0.5 & 0.5 & \pm & 0.4 & 0.71 \\
\hline Platelets $\left(10^{10} / \mathrm{L}\right)$ & 18.8 & \pm & 6.6 & 14.9 & \pm & 4.5 & 0.01 \\
\hline Albumin (g/dL) & 4.47 & \pm & 0.22 & 4.54 & \pm & 0.18 & 0.20 \\
\hline Uric acid (mg/dL) & 2.85 & \pm & 0.89 & 3.03 & \pm & 0.93 & 0.47 \\
\hline AST $(\mathrm{U} / \mathrm{L})$ & 29.2 & \pm & 10.6 & 32.3 & \pm & 14.4 & 0.40 \\
\hline $\operatorname{ALT}(\mathrm{U} / \mathrm{L})$ & 31.3 & \pm & 15.4 & 35.4 & \pm & 31.1 & 0.57 \\
\hline $\mathrm{FBG}(\mathrm{mg} / \mathrm{dL})$ & 101.2 & \pm & 13.1 & 104.5 & \pm & 17.0 & 0.44 \\
\hline
\end{tabular}

LSM, liver stiffness measurement; TAC, total antioxidative capacity; MDA, malondialdehyde; ROS, reactive oxygen species; GSH, glutathione; GPx, glutathione peroxidase; GRed, glutathione reductase; HA, hyaluronic acid; APRI, AST to platelet ratio index; FIB-4, fibrosis-4; TGF- $\beta 1$, transforming growth factor- $\beta 1$; PDGF, platelet-derived growth factor; AST, alkaline aspartate transaminase; ALT, alanine transaminase; FBG, fasting blood glucose.

In addition, we also compared the TAC and APRI levels according to the "active" versus "inactive" HBV carriers, which were divided by an HBV viral DNA load of $2000 \mathrm{IU} / \mathrm{mL}$ [43]. In general, the pathological features of HBV-derived chronic inflammation and hepatofibrosis are distinguished by the HBV DNA viral load, likely activation of DNA amplification, and the severity of liver injury [44]. Interestingly, TAC was more considerably altered according to the degree of liver fibrosis in inactive HBV carriers (34 subjects, $p=0.03$ ), while the APRI (but not FIB and HA) value was more prominent in the active HBV carrier group (20 subjects, $p=0.04$, Figure 2A-D). This result may indicate that antioxidant capacity may affect the fibrotic change in a more dominant manner in inactive HBV carriers than in active HBV carriers. Regarding the impact of the APRI as an indicator of hepatofibrotic progression, the decrease in platelet number and the increase in AST level in active HBV carriers are well known [45]. Although no significant difference was found in the level of serum transaminases between the mild and moderate/severe liver fibrosis group $(\mathrm{LSM}>8.5$ versus $\mathrm{LSM}<8.5$, AST $29.2 \pm 10.6 \mathrm{U} / \mathrm{L}$ versus $32.3 \pm 14.4 \mathrm{U} / \mathrm{L}$, 
$p=0.40$, ALT $31.3 \pm 15.4 \mathrm{U} / \mathrm{L}$ versus $35.4 \pm 31.1 \mathrm{U} / \mathrm{L}, p=0.57$, Table 2), our data showed an apparent high level of AST (but not platelet number) in active HBV carriers; furthermore, its level was increased according to the progression of hepatic fibrosis $(37.9 \pm 13.5 \mathrm{IU} / \mathrm{L}$ versus $26.5 \pm 9.5 \mathrm{IU} / \mathrm{L}, p<0.01$, Table S2). In addition, we analyzed the possible involvement of antiviral drugs (use or not), even though there were conflicting reports on the prooxidant and antioxidant properties of antiviral agents according to studies [21,46]. Moreover, we also found that the TAC level was notably lower in the moderate/severe fibrotic group (LSM > 8.5 versus $\mathrm{LSM}<8.5,424 \pm 136 \mu \mathrm{M} / \mathrm{mL}$ versus $524 \pm 166 \mu \mathrm{M} / \mathrm{mL}, p=0.06$, Table S3) among the antiviral drug use subjects (35 subjects), while the no-antiviral drug use subjects (19 subjects) also displayed an identical patten (LSM $>8.5$ versus $\mathrm{LSM}<8.5$, $390 \pm 154 \mu \mathrm{M} / \mathrm{mL}$ versus $486 \pm 88 \mu \mathrm{M} / \mathrm{mL}, p=0.11$, Table S4).

A

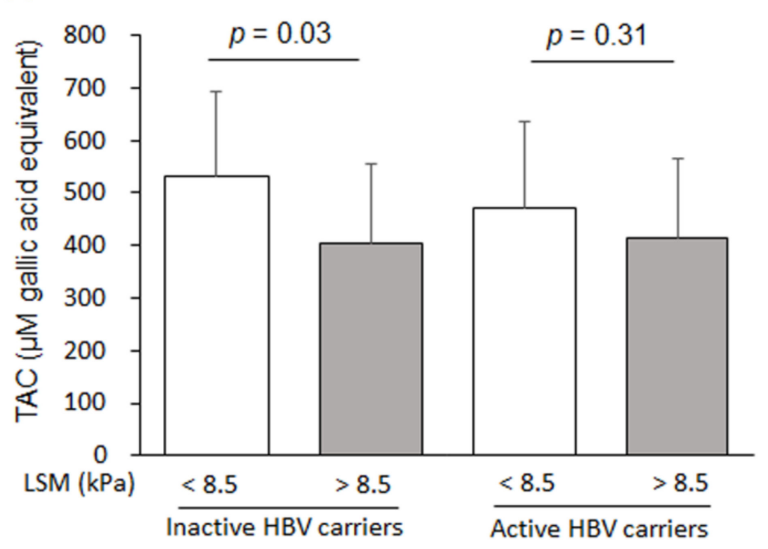

C

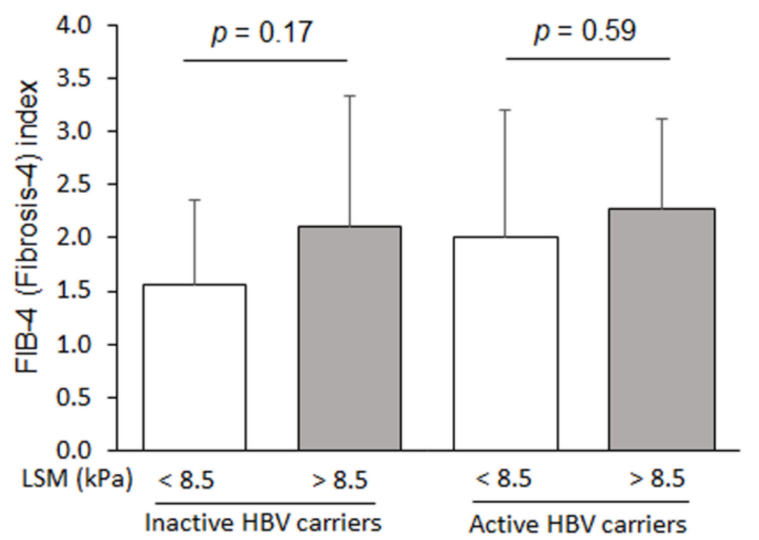

B

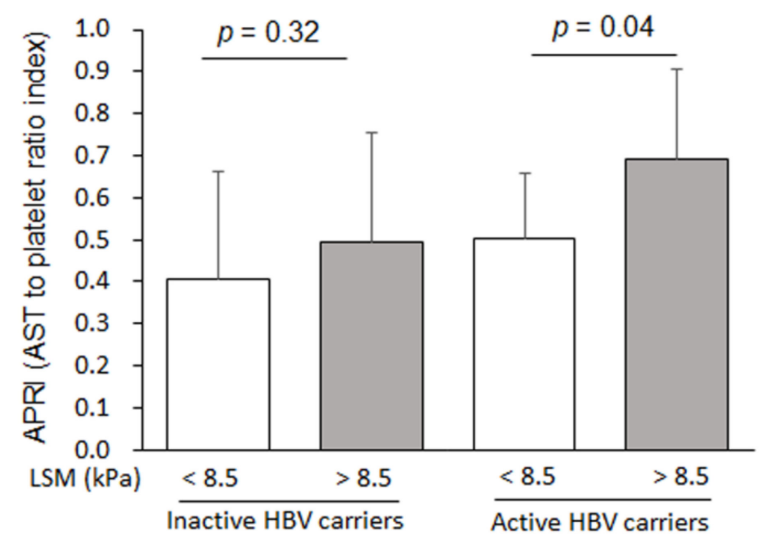

$\mathrm{D}$

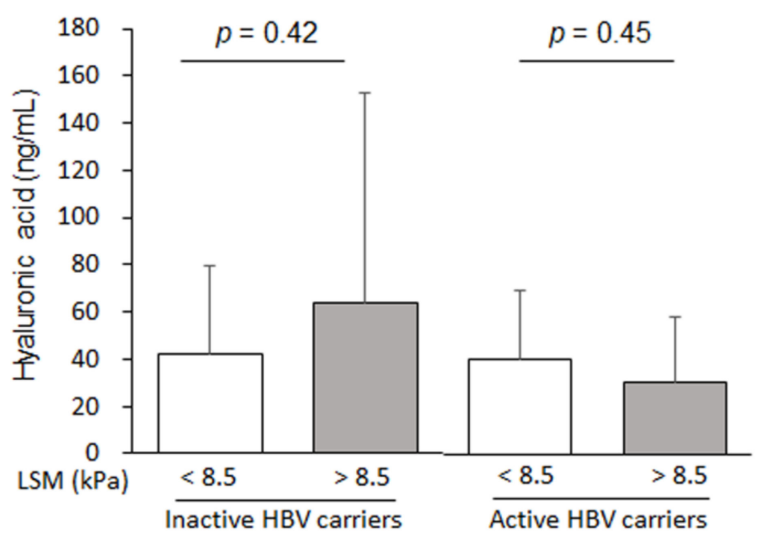

Figure 2. Comparison of the differences in fibrotic markers according to the level of HBV DNA load. The levels of TAC (A), APRI (B), FIB-4 (C), and Hyaluronic acid (D) were compared within the active (viral DNA load $>2000 \mathrm{IU} / \mathrm{mL}$ ) or inactive (viral DNA load < $2000 \mathrm{IU} / \mathrm{mL}$ ) HBV carriers according to the Liver Stiffness Measurement (LSM) score $(\mathrm{LSM}<8.5$ or $>8.5$ ).

Additionally, TAC and other oxidative stress/antioxidative parameters were compared according to gender difference. However, no significant difference was found in TAC and other oxidative stress/antioxidative parameters between male and female HBV carriers (data not shown). In subgroup analysis, we observed that the TAC levels were significantly lower in the moderate/severe fibrotic group (LSM $>8.5$ versus $\mathrm{LSM}<8.5$, $403 \pm 150 \mu \mathrm{M} / \mathrm{mL}$ versus $519 \pm 159 \mu \mathrm{M} / \mathrm{mL}, p=0.02$, Table S5) among the male subjects (44 subjects), while the female subjects (10 subjects) only showed a similar pattern, without statistical significance (LSM $>8.5$ versus $\mathrm{LSM}<8.5,461 \pm 17 \mu \mathrm{M} / \mathrm{mL}$ versus $516 \pm 79 \mu \mathrm{M} / \mathrm{mL}, p=0.13$, Table S6). A probable explanation is due to the small number of female samples. Although the significant difference in TAC level between the mild 
and moderate/severe liver fibrosis groups was not detected in female subjects, we cannot simply conclude that gender difference is a crucial factor in the causes of TAC change. Hence, a large sample size and balanced sex ratio should be taken into consideration in further studies.

\section{Conclusions}

Taken together, we can conclude that TAC might become a valuable indicator of the progression of liver fibrosis in HBV carriers, at least in males. As a simple alternative predictor, TAC can assist us to evaluate the extent of liver fibrosis in patients with chronic HBV, along with LSM and biopsies. A relatively small number of samples, especially female and young subjects, is a limitation of this pilot study. Further studies are needed using a large number of samples with evenly distributed age/gender and other causative conditions, such as hepatitis $\mathrm{C}$ and alcoholic/nonalcoholic chronic liver diseases.

Supplementary Materials: The following are available online at https:/ / www.mdpi.com/2076-3 921/10/1/77/s1, Table S1: Inclusion criteria and exclusion criteria, Table S2: Parameters change according to the HBV viral DNA load, Table S3: Parameters change in the antiviral drug use subjects according to the LSM score, Table S4: Parameters change in the no-antiviral drug use subjects according to the LSM score, Table S5: Liver fibrosis parameters change in male HBV carriers according to the LSM score, Table S6: Liver fibrosis parameters change in female HBV carriers according to the LSM score.

Author Contributions: Conceptualization, C.-G.S. and J.-H.W.; methodology, D.-S.L. and J.-H.W.; validation, C.-G.S.; formal analysis, J.-H.W.; investigation, J.-H.W. and S.-B.L.; resources, D.-S.L.; data curation, J.-H.W. and D.-S.L.; writing-original draft preparation, J.-H.W.; writing-review and editing, J.-H.W. and C.-G.S.; visualization, J.-H.W.; supervision, C.-G.S.; project administration, C.-G.S.; funding acquisition, C.-G.S. All authors have read and agreed to the published version of the manuscript.

Funding: This research was funded by the National Research Foundation of Korea (NRF), grant number 2019R1A2C2088201.

Institutional Review Board Statement: Ethical approval for the study was obtained from the institutional ethics committee of Daejeon University Dunsan Hospital (DJMC200901) and Daejeon St. Mary's Hospital of Catholic University of Korea (DC12MDMT0041).

Informed Consent Statement: Informed consent was obtained from all subjects involved in the study.

Data Availability Statement: The data that support the findings of this study are available from the corresponding author, [Son, C.-G], upon reasonable request.

Conflicts of Interest: The authors declare no conflict of interest.

\section{References}

1. Inoue, T.; Tanaka, Y. The Role of Hepatitis B Core-Related Antigen. Genes 2019, 10, 357. [CrossRef]

2. Nelson, N.P.; Easterbrook, P.J.; McMahon, B.J. Epidemiology of Hepatitis B Virus Infection and Impact of Vaccination on Disease. Clin. Liver Dis. 2016, 20, 607-628. [CrossRef]

3. World Health Organization. Guidelines for the Prevention, Care and Treatment of Persons with Chronic Hepatitis B Infection; WHO: Geneva, Switzerland, 2015.

4. Subic, M.; Zoulim, F. How to improve access to therapy in hepatitis B patients. Liver Int. 2018, 38 (Suppl. 1), 115-121. [CrossRef]

5. Altamirano-Barrera, A.; Barranco-Fragoso, B.; Mendez-Sanchez, N. Management strategies for liver fibrosis. Ann. Hepatol. 2017, 16, 48-56. [CrossRef]

6. Hsiao, C.Y.; Teng, X.; Su, T.H.; Lee, P.H.; Kao, J.H.; Huang, K.W. Improved quantitative assessment of HBV-associated liver fibrosis using second-harmonic generation microscopy with feature selection. Clin. Res. Hepatol. Gastroenterol. 2020, 44, 12-20. [CrossRef]

7. Barcena Marugan, R.; Garcia Garzon, S. DNA-guided hepatitis B treatment, viral load is essential, but not sufficient. World J. Gastroenterol. 2009, 15, 423-430. [CrossRef]

8. Li, S.; Hong, M.; Tan, H.Y.; Wang, N.; Feng, Y. Insights into the Role and Interdependence of Oxidative Stress and Inflammation in Liver Diseases. Oxidative Med. Cell. Longev. 2016, 2016, 4234061. [CrossRef] 
9. $\quad$ Luangmonkong, T.; Suriguga, S.; Mutsaers, H.A.M.; Groothuis, G.M.M.; Olinga, P.; Boersema, M. Targeting Oxidative Stress for the Treatment of Liver Fibrosis. Rev. Physiol. Biochem. Pharmacol. 2018, 175, 71-102. [CrossRef]

10. Sies, H. Oxidative stress: From basic research to clinical application. Am. J. Med. 1991, 91, 31S-38S. [CrossRef]

11. Pizzino, G.; Irrera, N.; Cucinotta, M.; Pallio, G.; Mannino, F.; Arcoraci, V.; Squadrito, F.; Altavilla, D.; Bitto, A. Oxidative Stress: Harms and Benefits for Human Health. Oxidative Med. Cell. Longev. 2017, 2017, 8416763. [CrossRef]

12. Chan, T.C.; Wilkinson Berka, J.L.; Deliyanti, D.; Hunter, D.; Fung, A.; Liew, G.; White, A. The role of reactive oxygen species in the pathogenesis and treatment of retinal diseases. Exp. Eye Res. 2020, 201, 108255. [CrossRef]

13. Vranova, E.; Inze, D.; Van Breusegem, F. Signal transduction during oxidative stress. J. Exp. Bot. 2002, 53, 1227-1236. [CrossRef]

14. Singal, A.K.; Jampana, S.C.; Weinman, S.A. Antioxidants as therapeutic agents for liver disease. Liver Int. 2011, 31, 1432-1448. [CrossRef]

15. Gong, Y.; Yang, Y. Activation of Nrf2/AREs-mediated antioxidant signalling, and suppression of profibrotic TGF-beta1/Smad3 pathway: A promising therapeutic strategy for hepatic fibrosis-A review. Life Sci. 2020, 256, 117909. [CrossRef]

16. Wong, G.L. Non-invasive assessments for liver fibrosis: The crystal ball we long for. J. Gastroenterol. Hepatol. 2018, 33, 1009-1015. [CrossRef]

17. Afdhal, N.H. Fibroscan (transient elastography) for the measurement of liver fibrosis. Gastroenterol. Hepatol. $2012,8,605-607$.

18. Yen, Y.H.; Kuo, F.Y.; Kee, K.M.; Chang, K.C.; Tsai, M.C.; Hu, T.H.; Lu, S.N.; Wang, J.H.; Hung, C.H.; Chen, C.H. APRI and FIB-4 in the evaluation of liver fibrosis in chronic hepatitis C patients stratified by AST level. PLoS ONE 2018, 13, e0199760. [CrossRef]

19. Gudowska, M.; Gruszewska, E.; Panasiuk, A.; Cylwik, B.; Flisiak, R.; Swiderska, M.; Szmitkowski, M.; Chrostek, L. Hyaluronic acid concentration in liver diseases. Clin. Exp. Med. 2016, 16, 523-528. [CrossRef]

20. Loaeza-del-Castillo, A.; Paz-Pineda, F.; Oviedo-Cardenas, E.; Sanchez-Avila, F.; Vargas-Vorackova, F. AST to platelet ratio index (APRI) for the noninvasive evaluation of liver fibrosis. Ann. Hepatol. 2008, 7, 350-357. [CrossRef]

21. Alavian, S.M.; Showraki, A. Hepatitis B and its Relationship with Oxidative Stress. Hepat. Mon. 2016, 16, e37973. [CrossRef]

22. Tapper, E.B.; Castera, L.; Afdhal, N.H. FibroScan (vibration-controlled transient elastography): Where does it stand in the United States practice. Clin. Gastroenterol. Hepatol. 2015, 13, 27-36. [CrossRef]

23. Satoh, K. Serum lipid peroxide in cerebrovascular disorders determined by a new colorimetric method. Clin. Chim. Acta 1978, 90, 37-43. [CrossRef]

24. Shankar, K.; Mehendale, H.M. Oxidative Stress. In Encyclopedia of Toxicology, 3rd ed.; Wexler, P., Ed.; Academic Press: Oxford, UK, 2014; pp. 735-737. [CrossRef]

25. Hayashi, I.; Morishita, Y.; Imai, K.; Nakamura, M.; Nakachi, K.; Hayashi, T. High-throughput spectrophotometric assay of reactive oxygen species in serum. Mutat. Res. 2007, 631, 55-61. [CrossRef]

26. Wheeler, C.R.; Salzman, J.A.; Elsayed, N.M.; Omaye, S.T.; Korte, D.W., Jr. Automated assays for superoxide dismutase, catalase, glutathione peroxidase, and glutathione reductase activity. Anal. Biochem. 1990, 184, 193-199. [CrossRef]

27. Kambayashi, Y.; Binh, N.T.; Asakura, H.W.; Hibino, Y.; Hitomi, Y.; Nakamura, H.; Ogino, K. Efficient assay for total antioxidant capacity in human plasma using a 96-well microplate. J. Clin. Biochem. Nutr. 2009, 44, 46-51. [CrossRef]

28. Zhang, Z.Q.; Shi, B.S.; Lu, W.; Liu, D.P.; Huang, D.; Feng, Y.L. Quantitative HBcrAg and HBcAb versus HBsAg and HBV DNA in predicting liver fibrosis levels of chronic hepatitis B patients. Gastroenterol. Hepatol. 2020, 43, 526-536. [CrossRef]

29. Parikh, P.; Ryan, J.D.; Tsochatzis, E.A. Fibrosis assessment in patients with chronic hepatitis B virus (HBV) infection. Ann. Transl. Med. 2017, 5, 40. [CrossRef]

30. Lin, L.; Zhou, F.; Shen, S.; Zhang, T. Fighting Liver Fibrosis with Naturally Occurring Antioxidants. Planta Med. 2018, 84, 1318-1333. [CrossRef]

31. Sanchez-Valle, V.; Chavez-Tapia, N.C.; Uribe, M.; Mendez-Sanchez, N. Role of oxidative stress and molecular changes in liver fibrosis: A review. Curr. Med. Chem. 2012, 19, 4850-4860. [CrossRef]

32. Gomez-Dominguez, E.; Mendoza, J.; Rubio, S.; Moreno-Monteagudo, J.A.; Garcia-Buey, L.; Moreno-Otero, R. Transient elastography: A valid alternative to biopsy in patients with chronic liver disease. Aliment. Pharmacol. Ther. 2006, $24,513-518$. [CrossRef]

33. Fung, J.; Lee, C.K.; Chan, M.; Seto, W.K.; Wong, D.K.; Lai, C.L.; Yuen, M.F. Defining normal liver stiffness range in a normal healthy Chinese population without liver disease. PLoS ONE 2013, 8, e85067. [CrossRef]

34. Linden, A. Measuring diagnostic and predictive accuracy in disease management: An introduction to receiver operating characteristic (ROC) analysis. J. Eval. Clin. Pract. 2006, 12, 132-139. [CrossRef]

35. Yang, J.; Xiong, Y.; Zhou, L.; Huang, Y.; Chen, W.; Wang, B. Soluble E-cadherin is associated with oxidative stress in patients with chronic HBV infection. J. Med. Virol. 2020, 92, 34-44. [CrossRef]

36. Duygu, F.; Karsen, H.; Aksoy, N.; Taskin, A. Relationship of oxidative stress in hepatitis B infection activity with HBV DNA and fibrosis. Ann. Lab. Med. 2012, 32, 113-118. [CrossRef]

37. Rubio, C.P.; Hernandez-Ruiz, J.; Martinez-Subiela, S.; Tvarijonaviciute, A.; Ceron, J.J. Spectrophotometric assays for total antioxidant capacity (TAC) in dog serum: An update. BMC Vet. Res. 2016, 12, 166. [CrossRef]

38. Sies, H. Total antioxidant capacity: Appraisal of a concept. J. Nutr. 2007, 137, 1493-1495. [CrossRef]

39. Erel, O. A novel automated direct measurement method for total antioxidant capacity using a new generation, more stable ABTS radical cation. Clin. Biochem. 2004, 37, 277-285. [CrossRef] 
40. Bernardi, M.; Maggioli, C.; Zaccherini, G. Human albumin in the management of complications of liver cirrhosis. Crit. Care 2012, 16, 211. [CrossRef]

41. Jang, T.Y.; Yeh, M.L.; Huang, C.I.; Lin, Z.Y.; Chen, S.C.; Hsieh, M.H.; Dai, C.Y.; Huang, J.F.; Huang, C.F.; Chuang, W.L.; et al. Association of hyperuricemia with disease severity in chronic hepatitis C patients. PLoS ONE 2018, 13, e0207043. [CrossRef]

42. Plantier, J.L.; Duretz, V.; Devos, V.; Urbain, R.; Jorieux, S. Comparison of antioxidant properties of different therapeutic albumin preparations. Biologicals 2016, 44, 226-233. [CrossRef]

43. Oliveira, V.O.; Oliveira, J.P.; Franca, E.V.; Brito, H.L.; Nascimento, T.V.; Franca, A. Advanced liver injury in patients with chronic hepatitis b and viral load below $2000 \mathrm{IU} / \mathrm{mL}$. Rev. Inst. Med. Trop. Sao Paulo 2016, 58, 65. [CrossRef]

44. Tong, M.J.; Pan, C.Q.; Hann, H.W.; Kowdley, K.V.; Han, S.H.; Min, A.D.; Leduc, T.S. The management of chronic hepatitis B in Asian Americans. Dig. Dis. Sci. 2011, 56, 3143-3162. [CrossRef]

45. Ijaz, B.; Ahmad, W.; Javed, F.T.; Gull, S.; Hassan, S. Revised cutoff values of ALT and HBV DNA level can better differentiate HBeAg (-) chronic inactive HBV patients from active carriers. Virol. J. 2011, 8, 86. [CrossRef]

46. Proskurnina, E.V.; Izmailov, D.Y.; Sozarukova, M.M.; Zhuravleva, T.A.; Leneva, I.A.; Poromov, A.A. Antioxidant Potential of Antiviral Drug Umifenovir. Molecules 2020, 25, 1577. [CrossRef] 